\title{
Deaths of Irish Civilians Abroad: Analysis of National Mortality Data, 2016-2018
}

\author{
Milad Darrat', Gerard T. Flaherty ${ }^{1,2 *}$ \\ ${ }^{1}$ School of Medicine, National University of Ireland Galway, Ireland \\ ${ }^{2}$ School of Medicine, International Medical University, Kuala Lumpur, Malaysia \\ Corresponding Author: Gerard T. Flaherty, MD, Professor, School of Medicine, National University of Ireland \\ Galway, Galway, Ireland. Tel: +353-91495469, Fax: +353-91494540, Email: gerard.flaherty@nuigalway.ie
}

Received October 9, 2018; Accepted November 4, 2018; Online Published November 28, 2018

\begin{abstract}
Introduction: International travel is increasing, yet few studies have reported on country-level death rates among international travelers. The data regarding the death profiles of overseas Irish travelers are insufficient. The current study examined data obtained from the Irish Department of Foreign Affairs and Trade to profile these deaths.

Methods: Data on Irish civilian citizen deaths occurring abroad were obtained from the Consular Division of the Irish Department of Foreign Affairs and Trade and analyzed based on age, gender, time of death, travel destination, and recorded cause of death.

Results: Between January 2016 and April 2018, the Consular Division received 654 reports of Irish civilians dying abroad, of which $72 \%$ $(n=469)$ were males and $23 \%(n=149)$ were females; in $6 \%(n=36)$ the sex was not recorded. The mean age at death was $58 \pm 5$ years old (range from 1 to 110, median 62 years). Recorded causes of death were illness (25\%; $\mathrm{n}=162$ ), traumatic deaths including homicides and suicides ( $24 \% ; n=151)$, and natural (age-related) $(3 \% ; n=19)$; the rest were classified as unidentified cause $(47 \% ; n=309)$. The majority of deaths $(63 \% ; n=309)$ occurred in European destinations followed by Asia $(16 \% ; n=102)$ and the Americas $(12 \% ; n=75)$.

Conclusion: At least $25 \%$ of Irish deaths abroad can be considered preventable. More tailored pre-travel medical interventions may prevent further deaths. In the collection of data, consular services miss the opportunity to acquire valuable information for both travelers and healthcare professionals. The authors recommend the creation of a comprehensive database of international traveler deaths.

Keywords: Irish, Civilians, International Travel, Death, Overseas
\end{abstract}

Citation: Darrat M, Flaherty GT. Deaths of Irish civilians abroad: Analysis of National Mortality Data, 2016-2018. Int J Travel Med Glob Health. 2018;6(4):149-153. doi:10.15171/ijtmgh.2018.27.

\section{Introduction}

As a result of the lower cost of flights, many people have had an opportunity to travel to distant countries for purposes of tourism, study, business, migration, and missionary activities. ${ }^{1}$ Of the more than one billion travelers who travel overseas each year, many are at a higher risk of falling severely ill, being injured, or even dying from either natural or unnatural causes. ${ }^{1}$ Several studies in the field of travel medicine have investigated deaths among travelers. Of particular interest are those which have investigated deaths during flights ${ }^{2}$; others have investigated deaths due to specific causes such as cardiovascular diseases,,${ }^{2,3}$ infectious diseases, ${ }^{4}$ trauma and road accidents, ${ }^{5-8}$ and envenomation. ${ }^{9}$

Deaths attributed to travel can be classified into two categories, the general population and younger adults working in developing countries. ${ }^{2,3,5,10}$ Although the methodologies employed by the various studies conducted on this particular subject were difficult to compare, there were significant common conclusions that could be drawn. Many overseas deaths could be attributed to fatal injuries linked mostly to motor vehicle accidents and cardiovascular diseases associated more with elderly travelers. ${ }^{10}$ As a further illustration of the age-related comparison, a study of 98 Amsterdam residents aged 0-14 years who had died abroad attributed most of the deaths to accidents (especially motor vehicle-related ones), congenital anomalies, and gastrointestinal infections. ${ }^{11}$

An Australian study concluded that the crude mortality rate for short-term overseas travelers was around $0.1 \%$ of all deaths annually. ${ }^{12}$ Cardiovascular diseases effected $35 \%$ of overseas deaths overseas, natural causes accounted for $50 \%$, and trauma led to $25 \%$ of deaths of Australians abroad. ${ }^{12}$ Europe, Central and South America were found to be the most dangerous places for Australian tourists. ${ }^{12}$ A similar pattern was also observed in Swiss, American, and Canadian travelers; most fatal incidents were either traffic or swimming accidents. ${ }^{13-16}$ A Scottish study analyzed 572 Scottish deaths

Copyright $\odot 2018$ The Author(s). This is an open-access article distributed under the terms of the Creative Commons Attribution License (http:// creativecommons.org/licenses/by/4.0), which permits unrestricted use, distribution, and reproduction in any medium, provided the original work is properly cited. 
reported abroad between 2000 and 2004, 73\% occurring in European regions and $10 \%$ in the Americas. Of these deaths, $1.5 \%$ were linked to infectious diseases, $20.4 \%$ to trauma, and $75.5 \%$ were caused by non-infectious factors. ${ }^{15}$

Despite numerous reports of travel-related deaths, establishing the events leading to them has proven to be difficult. Pretravel medical advice often focuses on infectious diseases, leaving a lack of details on other fatal incidents, although exceptions do exist. ${ }^{17,18}$ In the Republic of Ireland, publicly available details from death reports on the mortality of Irish people abroad are limited. The number, cause, and location (country) of the deaths of traveling Irish civilians have not been previously analyzed. The current study used a national data collection system to report on Irish deaths occurring abroad. To the best of the authors' knowledge, this study is the first ever to use data from the Irish Department of Foreign Affairs and Trades (DoFA) and to analyze the death reports of Irish civilian overseas travelers.

\section{Methods}

\section{Study Design and Data Source}

In this study, a descriptive, retrospective analysis of aggregated data was performed. Information on the deaths of Irish nationals occurring abroad was obtained from the Consular Division of the DoFA. All records available in the DoFA office relating to the deaths of Irish civilians of all ages occurring abroad between the period of January 2016 and April 2018 were reviewed.

\section{Data Analysis}

Demographic details of the deceased and data related to age, gender, region and country where death occurred, time of death, and cause of death were extracted. For the purpose of this study and due to limitations of the data source, the specific terminology used to indicate cause of death was similar across entries, resulting in consistent classification by cause of death. The countries where death occurred were clustered by region according to the six regions of the WHO. ${ }^{19}$ Data was analyzed using Microsoft Excel, version 2017. Qualitative data was presented using frequency and percentiles, while quantitative data was presented using mean and standard deviation. The F-test was also used to analyze the significance of deaths in terms of age and time of death. $P$ values were reported for comparisons of specific interest; a $P$ value $<0.05$ was considered as statistically significant.

\section{Data Limitations}

Significant difficulty was encountered in estimating the number of Irish deaths abroad and their attributive causes. According to the DoFA, there is no particular obligation for relatives of the deceased to inform the Irish consulates of a loved one's death. Furthermore, not only was the data centrally collated, but also dependence on close family members of the deceased to report the deaths was quite limiting, as they may not have been in a position to give the correct cause of death. In the case of repatriation and burials in Ireland, the Registrar of Birth, Deaths, and Marriages for the district must be notified before the burial takes place once the body arrives in the country. However, for this study, it was not possible to collect data from those officials on specific causes of death or on where the deaths occurred.

The mentioned challenges made it difficult to determine the representativeness of the sample used in estimating the actual number of Irish citizens dying abroad. Information on traveler type, time spent abroad, risk factors, and data on pre-existing medical conditions was not available. Bias was also observed in recording causes of death between different countries due to varying national factors and policies. Finally, the data on cause of death did not differentiate between Irish citizens living abroad (such as expatriates) and those traveling abroad (such as tourists). This may have led to biased comparisons in reference to Irish populations. For example, an extended stay abroad may have had an impact on the causes of death, such as diseases or accidents, as well as age-specific factors.

\section{Results}

A total of 654 deaths were reported to the Consular Division of the DoFA between January 2016 and April 2018. Of these, $72 \%(n=469)$ of the deceased were males and $23 \%$ $(n=149)$ were females; in $6 \%(n=36)$ of cases, the sex was not documented. The mean age at death was $58 \pm 5$ years old (range from 1 to 110 , with median 62 years old).

\section{Causes of Death}

Cause of death was recorded in $98 \%(n=641)$ of death reports received by the Consular Division. However, in nearly half of those reports, accurately ascertaining the cause of death was difficult, because they were classified as unidentified cause of death (Figure 1). Of the other half, only 3\% $(n=19)$ of deaths were reported as being due to natural causes (advanced agerelated deaths). Traumatic deaths accounted for $24 \%(n=151)$ and were described as the results of accidental death, road accident, suicide, and homicide. The remainder of causes of death consisted of those who died as a consequence of short-term 19\% $(n=122)$ or long-term illnesses $6 \%(n=40)$ (Table 1).

\section{Geographic Distribution of Fatalities}

In all regions, the total number of deaths reported based on destination was $97 \%(n=636)$ (Figure 2$)$. The majority of deaths occurred in Europe, with European destinations accounting for $63 \%(n=404)$ of deaths followed by Asia $(16 \%$; $\mathrm{n}=102)$, then the Americas $(12 \% ; \mathrm{n}=75)$, Oceania $(6 \%$; $n=38)$, and Africa $(3 \% ; n=17)$. The five countries where most of the deaths over the three-year study period occurred were Spain $(28 \% ; n=175)$, Great Britain $(14 \% ; n=88)$, Thailand $(7 \% ; n=44)$, USA $(7 \% ; n=43)$, and Australia $(6 \% ; n=34)$. The African country where deaths most frequently occurred was South Africa $(1 \% ; n=4)$, while in the Middle East region, most deaths occurred in the United Arab Emirates (2\%; $\mathrm{n}=10)$.

\section{Age Distribution, Regional and Seasonal Variations}

A large variance was observed with regard to age, gender, region and time of death. The mean number of deaths per region over the three-year period showed that Southern 


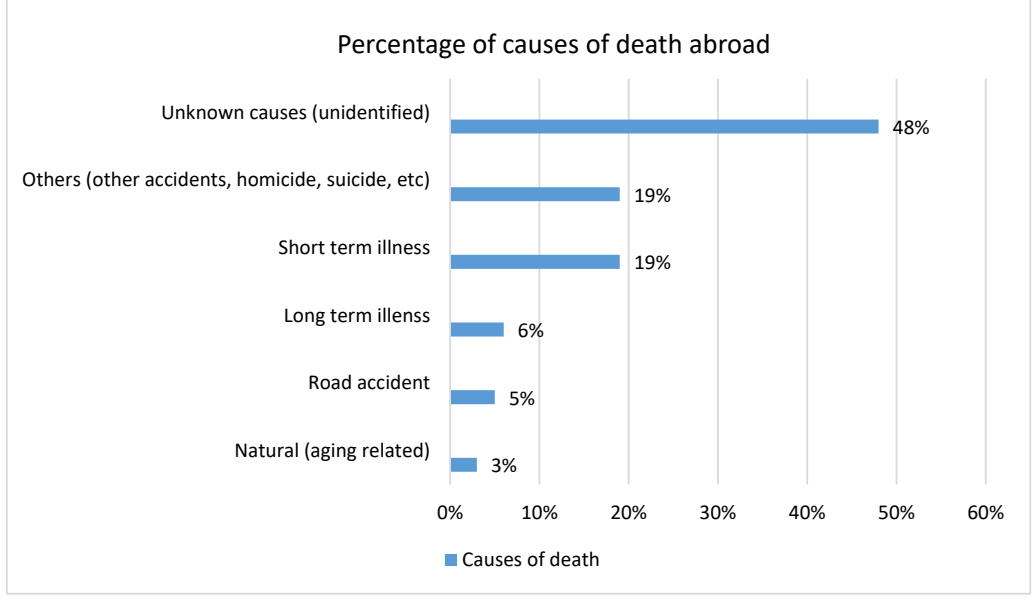

Figure 1. Causes of Death of Irish Travelers Abroad.

Europe, encompassing countries such as Spain, Portugal, France, Greece, Malta, Italy (Turkey was also considered as part of the southern region for the purposes of this research), had the highest mean age of death for both males and females at 61.81 years. The leading causes of death in the region included unknown reason, illnesses, and accidents, respectively. Importantly, the same region had the largest number of reported deaths over the three-year study period comprising 37\%-39\% of the total number of reported deaths. The lowest mean age at time of death over the study period was seen in the Indian Ocean region (which included Maldives, India, and Sri Lanka) at 13.83 years. The number of reported deaths from this region averaged 1\% from 2016 to 2017 , increasing to $6 \%$ in 2018 . Notably, over the threeyear study period, the number of deaths reported from Africa

Table 1. Causes of Death by Gender

\begin{tabular}{lcc}
\hline Total Sample Size $(\mathbf{N}=\mathbf{6 5 4})$ & Male, No. $\mathbf{( \% )}$ & Female, No. (\%) \\
\hline Cause & $58(9)$ & $14(2)$ \\
\hline Accidental death & $25(4)$ & $5(1)$ \\
Road accident & $95(15)$ & $27(4)$ \\
Short-term illness & $24(4)$ & $16(2)$ \\
Long-term illness & $14(2)$ & $5(1)$ \\
Natural (advanced age-related death) & $236(37)$ & $73(11)$ \\
Unknown Reasons & $42(7)$ & $7(1)$ \\
Others (suicide, overdose etc.) & & \\
\hline
\end{tabular}

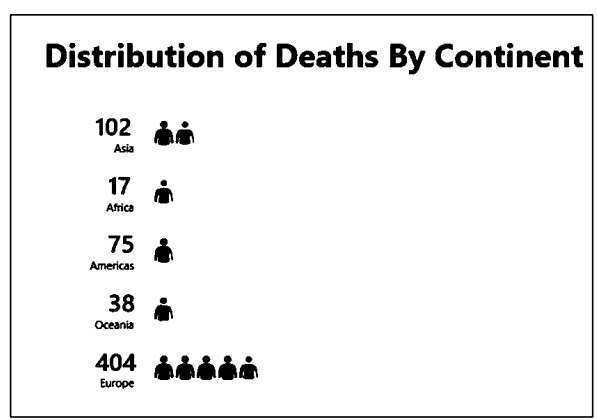

Figure 2. Distribution of Deaths by Continent. was stable at just $1 \%$. The percentage of females dying abroad was considerably lower than that of males with a statistically significant difference $(P \leq 0.05)$. The majority of deaths occurred for people between the ages of 60 and 74 years. The fewest deaths occurred in the age groups 0-20 and 101-120 years (Table 2). Younger persons died more in places such as the Middle East, China, and Thailand. Older individuals died more frequently in Europe compared to other places.

The F-test two-sample for variances, another statistical tool, was used to analyze the variation of deaths in terms of seasons. Using the data for the three-year study period, a value of $P=0.03$ showed that there is a variation in the number of deaths occurring in summer and those occurring in winter. A strong correlation exists between the season and number of deaths reported; more deaths are reported in summer than in winter across all continents.

\section{Discussion}

In 2017, the DoFA provided support to over 2500 Irish citizens in distress abroad. ${ }^{18}$ This involved assisting in situations involving missing persons, health welfare concerns, and arrest cases. ${ }^{20}$ The current study was carried out to estimate the number and to understand the typical profile of Irish deaths abroad. For the 28-month study period between 2016 and 2018, 645 deaths reported, which is more than the 572 deaths reported in a similar Scottish study published in 2011 for the 4-year period 2000 to $2004 .{ }^{16}$ Regrettably, there were over 300 bereavements of Irish citizens overseas in 2017, the

Table 2. Distribution of Deaths by Age and Gender

\begin{tabular}{lcc}
\hline Total Sample Size $(\mathbf{N}=\mathbf{6 5 4})$ & Male, No. $(\%)$ & Female, No. $\mathbf{\%})$ \\
\hline Cause & & \\
\hline Age & $16(2)$ & $5(1)$ \\
$1-20$ & $98(15)$ & $23(4)$ \\
$21-40$ & $112(17)$ & $31(5)$ \\
$41-60$ & $162(25)$ & $58(9)$ \\
$61-80$ & $43(7)$ & $13(2)$ \\
$81-100$ & $1(0.2)$ & $0(0)$ \\
$101-120$ & & \\
\hline
\end{tabular}


highest number of deaths the DoFA had ever dealt with in a single year. ${ }^{20}$ This observed increase in average number of deaths among travelers per year may reflect either increased numbers of deaths abroad as observed elsewhere, ${ }^{21-24}$ and/or an increase in the number of overseas visits observed among the Irish population. The Irish Central Statistics Office (CSO) estimated 7.9 million visits abroad were made by Irish residents in 2017. This may still suggest a low death rate considering the number of deaths per 100000 visits. $^{25}$

As in earlier studies, ${ }^{6,12,15,26}$ death reports were more commonly of males than of females (male/female ratio = 3:1). This detail should not be understood as indicating that males are at greater risk of dying while traveling, as the distribution of males and females traveling in these cohorts was not known.

In this study, a significant number of deaths (24\%) were caused by trauma, of which the majority were the results of accidents. Accidental deaths among travelers have also increased among citizens of other countries. It is argued that pre-travel advice tends to focus mainly on infectious disease risks rather than risks that result in injuries. ${ }^{6,5,24,27}$ It is, therefore, suggested that personal preparedness and planning is crucial in increasing safety and decreasing accident risks, as most overseas travelers are not familiar with local conditions and behaviors in foreign states that may lead to unfortunate types of accidents. ${ }^{28,29}$

Southern Europe as a travel destination had the highest number of deaths caused by accident compared with the rest of the world. Notably, Irish people who died in Europe were considerably older than those dying in other regions. For instance, the mean age at death in southern Europe was 61.81 years for the three-year study period; the mean age was 27 years for those dying in the Far East, including places like South Korea and Japan. This was also observed in a similar Scottish study. ${ }^{16}$ The factors related to the highest number of deaths occurring in this region may include the larger number of Irish travelers going to Southern Europe, the older age of travelers to this region, the presence of preexisting conditions, and/or environmental factors such as a hot climate. It would be interesting to study at which stage of the journey to Southern Europe deaths of Irish travelers occur.

Historically, the focus of pre-travel advice has been more toward measures for preventing infectious diseases rather than non-infectious events. ${ }^{30,31}$ However, the figures calculated in this analysis demonstrate the sizeable risk posed by nonnatural injury-related deaths and in more developed regions of the world. Therefore, in pre-travel medical consultations, it would be prudent to conduct a comprehensive, detailed risk assessment which incorporates geographical itinerary and individual's medical history while factoring in the traveler's risk-taking behaviors. With the provision of such evaluations and equal compliance by the travelers, the number of deaths of Irish civilians abroad would be reduced.

The current study was limited by a lack of access to death certificates and autopsy reports. Non-standardized reporting and examination of death in foreign countries have been identified in previous studies as potential sources of bias in

\section{Research Highlights}

\section{What Is Already Known?}

Pre-travel consultations tend to focus on the prevention of travel-related infectious diseases in tropical and sub-tropical destinations. There are limited country-level data available about the causes of mortality in international travelers.

\section{What This Study Adds?}

Majority of deaths in Irish citizens abroad occurred in older male travelers and were attributed almost equally to illness and trauma. This study points to the limitations of data held by national agencies and recommends the establishment of a comprehensive database of civilian travelrelated fatalities.

reported causes of death abroad. ${ }^{15,32,33}$ Nonetheless, this study has yielded useful insights into the number and characteristics of Irish deaths abroad. This study will also help in the development of more specialized travel healthcare services and education in the state. Further studies with larger sample sizes should be conducted at various times in an effort to further characterize the typical profile of Irish deaths abroad.

\section{Conclusion}

At least $25 \%$ of Irish deaths occurring abroad can be considered preventable. While travel consultations in Ireland often focus on those traveling to high-risk destinations for infectious diseases, the largest proportion of travelers are to Europe. Here, it was observed that the largest numbers of deaths among Irish travelers occurred in Europe and, to a lesser degree, Asia. More tailored pre-travel medical advice could have prevented further deaths. In the collection of data, consular services miss the opportunity to acquire valuable information for both travelers and healthcare professionals. It is recommended that a comprehensive traveler's database of greater use than that currently available be developed.

\section{Authors' Contributions}

MD was responsible for data collection and interpretation and prepared the first draft of the manuscript. GTF was responsible for study conception, data interpretation and editing of the manuscript. Both authors read and approved the final version of the manuscript.

\section{Conflicts of Interest Disclosures}

The authors declare that there is no conflict of interest.

\section{Ethical Approval}

This study did not require ethics committee approval.

\section{Funding/Support}

No funding sources.

\section{Acknowledgments}

The authors wish to express their gratitude to all team members at the Consular Division of the Department of Foreign Affairs and Trades, Dublin 2, Dublin, Ireland. 


\section{References}

1. Centers for Disease Control and Prevention CDC, Brunette GW. CDC Yellow Book 2018: health information for international travel. Oxford University Press; 2017.

2. Heckmann JG, Stemper B, Ringwald J, Nixdorff U, Neundorfer B. Economy class stroke syndrome. Cerebrovasc Dis. 2004;17(1):88. doi:10.1159/000073908

3. Lazicic-Putnik L, Rac OD, Lazaric-Zec D. Causes of death of foreign tourists in the county of Istria during the summer holiday season from 2000 to 2004. Int Marit Health. 2005;56(1-4):129134.

4. Newman RD, Parise ME, Barber AM, Steketee RW. Malariarelated deaths among U.S. travelers, 1963-2001. Ann Intern Med. 2004;141(7):547-555. doi:10.7326/0003-4819-141-7200410050-00012.

5. Cortes LM, Hargarten SW, Hennes HM. Recommendations for water safety and drowning prevention for travelers. J Travel Med. 2006;13(1):21-34. doi:10.1111/j.1708-8305.2006.00002.x.

6. Tonellato DJ, Guse CE, Hargarten SW. Injury deaths of US citizens abroad: new data source, old travel problem. J Travel Med. 2009;16(5):304-310. doi:10.1111/j.1708-8305.2009.00318.x.

7. Shaw MT, Leggat PA. Life and death on the Amazon: illness and injury to travelers on a South American expedition. J Travel Med. 2003;10(5):268-271. doi:10.2310/7060.2003.2694.

8. Long IJ, Flaherty GT. Silent killer-the dangers of carbon monoxide poisoning during international travel. J Travel Med. 2017;24(3). doi:10.1093/jtm/tax002

9. Fenner PJ. Dangers in the ocean: the traveler and marine envenomation. I. jellyfish. J Travel Med. 1998;5(3):135-141. doi:10.1111/j.1708-8305.1998.tb00487.x.

10. Leggat PA, Fischer PR. Accidents and repatriation. Travel Med Infect Dis.2006;4(3-4):135-146.doi:10.1016/j.tmaid.2005.06.008.

11. van der Wal MF, van Weert-Waltman ML, Reijneveld SA. [Causes of death in Amsterdam children who died abroad, 1982-1993; potential for prevention]. Ned Tijdschr Geneeskd. 1996;140(14):777-781.

12. Prociv P. Deaths of Australian travellers overseas. Med J Aust. 1995:163(1):27-30.

13. Steffen R. Travel medicine--prevention based on epidemiological data. Trans R Soc Trop Med Hyg. 1991;85(2):156-162. doi:10.1016/0035-9203(91)90005-J.

14. Baker TD, Hargarten SW, Guptill KS. The uncounted dead-American civilians dying overseas. Public Health Rep. $1992 ; 107(2): 155-159$.

15. MacPherson DW, Guerillot F, Streiner DL, Ahmed K, Gushulak BD, Pardy G. Death and dying abroad: the Canadian experience. J Travel Med. 2000;7(5):227-233. doi:10.2310/7060.2000.00070.

16. Redman CA, MacLennan A, Walker E. Causes of death abroad: analysis of data on bodies returned for cremation to Scotland. J Travel Med. 2011;18(2):96-101. doi:10.1111/j.17088305.2010.00486.x.

17. Freedman DO, Weld LH, Kozarsky PE, et al. Spectrum of disease and relation to place of exposure among ill returned travelers. $\mathrm{N}$
Engl J Med. 2006;354(2):119-130. doi:10.1056/NEJMoa051331.

18. Han CT, Flaherty G. Profile of Travelers With Preexisting Medical Conditions Attending a Specialist Travel Medicine Clinic in Ireland. J Travel Med. 2015;22(5):312-317. doi:10.1111/jtm.12221.

19. World Health Organization (WHO). WHO Member States. Geneva: WHO; 2018. http://www.who.int/about/regions/en/. Updated July 28, 2018. Accessed August 4, 2018.

20. Department of Foreign Affairs and Trade. Assistance to Irish citizens abroad. Dublin: 2018. https://www.dfa.ie/travel/statistics/. Updated August 4, 2018. Accessed August 5, 2018.

21. Partridge $R$, Bouslough D, Proano L. Disaster-related fatalities among US citizens traveling abroad. Am J Disaster Med. 2013;8(2):123-126. doi:10.5055/ajdm.2013.0118.

22. Vidua RK, Dubey N, Pramanik P, Mattoo SK, Jakher N. A Representative Study of Deaths of North Indian Migrants and Its Medical Certification Across the World. J Immigr Minor Health. 2018;20(1):73-82. doi:10.1007/s10903-016-0504-1.

23. Gaikwad PB, Khandare KP, Dan A, Jalaluddeen $M$, Pasi $A R$, Singh SK. Profile of Indians died abroad: analysis of secondary data of human remains arrived at point of entry in Mumbai. Int Community Med Public Health. 2018;5(8):5. doi:10.18203/2394 6040.ijcmph20183101.

24. Lawson CJ, Dykewicz CA, Molinari NA, Lipman H, AlvaradoRamy $\mathrm{F}$. Deaths in international travelers arriving in the United States, July 1, 2005 to June 30, 2008. J Travel Med. 2012;19(2):96103. doi:10.1111/j.1708-8305.2011.00586.x.

25. Central Statistics Office (CSO). Overseas Travel. Cork: CSO; 2018. https://www.cso.ie/en/statistics/tourismandtravel/overseastravel/. Updated August 2, 2018. Accessed August 5, 2018.

26. Lunetta P. Injury deaths among Finnish residents travelling abroad. Int J Inj Contr Saf Promot. 2010;17(3):161-168. doi:10.1080/17457300903453112.

27. Flaherty G, Hession M, Cuggy C. Hotel fire safety for international travellers. Travel Med Infect Dis. 2016;14(5):529-530. doi:10.1016/j.tmaid.2016.05.011.

28. Cornall P, Howie S, Mughal A, et al. Drowning of British children abroad. Child Care Health Dev. 2005;31(5):611-613. doi:10.1111/ j.1365-2214.2005.00534.x.

29. Guse CE, Cortes LM, Hargarten SW, Hennes HM. Fatal injuries of US citizens abroad. J Travel Med. 2007;14(5):279-287. doi:10.1111/j.1708-8305.2007.00133.x.

30. Bunn WB. Knowledge, attitudes, and practices of US practitioners who provide pre-travel advice. J Travel Med. 2015;22(1):70-71. doi:10.1111/jtm.12169.

31. Wadhwaniya S, Hyder AA. Pre-travel consultation without injury prevention is incomplete. J Travel Med. 2013;20(4):217-220. doi:10.1111/jtm.12041.

32. Nikku BR. Migration and worker fatalities abroad. Transnational Social Review. 2018;8(2):218-220. doi:10.1080/21931674.2018. 1463050.

33. Connolly R, Prendiville R, Cusack D, Flaherty G. Repatriation of human remains following death in international travellers. J Travel Med. 2017;24(2). doi:10.1093/jtm/taw082. 